\title{
Calculation and Management for Mining Loss and Dilution under 3D Visualization Technical Condition
}

\author{
Weijing Wang ${ }^{1}$, Shaofeng Huang ${ }^{2}$, Xiaobo $\mathrm{Wu}^{2}$, Qingfei $\mathrm{Ma}^{2}$ \\ ${ }^{1}$ University of Science \& Technology, Beijing, China; ${ }^{2}$ China National Gold Group Corporation, Beijing, China. \\ Email: huangshf@chinagoldgroup.com
}

Received April 13 ${ }^{\text {th }}$, 2011; revised April 26 ${ }^{\text {th }}, 2011$; accepted May 5 ${ }^{\text {th }}, 2011$.

\begin{abstract}
The mining loss rate and dilution rate are the key indicators for the mining technology and management level of mining enterprises. Aiming at the practical problems such as the large workload but inaccurate data of the traditional loss and dilution calculation method, this thesis introduces the operating principle and process of calculating the loss rate and dilution rate at the mining fields by adopting geological models. As an example, authors establishes $3 D$ models of orebody units in the exhausted area and mining fields in Yangshu Gold Mine in Liaoning Province, and conduct Boolean calculation among the models to obtain the calculation parameters of loss and dilution, and thereby calculate out the dilution rate and loss rate of the mining fields more quickly and accurately.
\end{abstract}

Keywords: Calculation and Management, Mining Loss and Dilution, 3D Visualization Introduction

\section{Introduction}

The mining loss rate and dilution rate not only are the major technical basis for the production organization and management of mines, but also are the key indicators for embodying the mining technical levels of mines. The sizes of the mining loss rate and dilution rate reflect the utilization ratio of mineral resources; furthermore, they directly influence the economic benefit of the mining enterprises. Therefore, the calculation and management of mining loss rate and dilution rate have been being treated as the central work of mining industry over a long time and also is the technical subject for a lot of supervisory engineering staffs to study and solve constantly [1].

The traditional statistical method of loss and dilution is: After every a certain mining height (scope), the geologic surveyors will conduct acceptance check, actual measurement and sampling works in the mining fields, whereafter, they will draft the surveyed drawing of acceptance and calculate the loss rate and dilution rate of every layer of minerals according to the acceptance check, actual measurement and sampled data every time. Inevitably, the traditional statistical method of loss and dilution indicators has such problems as large workload and inaccurate data exits and usually, which can not reflect the practical development and utilization degree of the mineral resources in the mines and influences the scientific production of mines.

It is an inevitable trend to promote the mining information management for quickly and accurately working out the dilution rate and loss rate of the mining fields. In this thesis, the authors 1) take the Yangshu Gold Mine in Liaoning Province as a example and conduct the application study and the software Micromine according to the operating principle and method of loss rate and dilution rate; 2) process the exploration in the calculation method for mining loss rate and dilution rate in mines according to the operating principle and method of loss rate and dilution rate at mining fields by establishing geological models, to provide a kind of more convenient and efficient management method for loss rate and dilution rate and offer beneficial explorations for improving the utilization efficiency of resources[2].

\section{Working Theory and Method}

\subsection{Concept of the Loss and Dilution}

As for the calculation and management for traditional loss and dilution during the mining process, explored geologic resources can not be completely extracted and utilized due to the restriction of such factors as orebody 
occurrence conditions, mining process, metallurgical processing technology and production management. The quantity of un-extracted ores or extracted and un-discharged ores in the balance sheet that are left behind under the ground is called ore loss, which can be divided into mining loss and non-mining loss. The former refers to the un-extracted ores or extracted but un-discharged ores that are left in the mining field; the latter refers to the safety pillars left due to geological and hydrogeological factors as well as for protecting shaft building structures. Loss rate is generally adopted to represent the variation degree of ores from quantity during the mining process. Loss rate is the percentage of lost ore quantity or metal quantity to industrial reserve or metal quantity during the mining process. Ore loss shall be examined by two different indicators. One is the industrial ore quantity loss rate (hereinafter referred to as ore loss rate) for calculating the ore loss in the mining field, mining team or work area.

The other is the ore quantity loss rate in the balance sheet, for calculating the ore loss of orebody. Industrial ore quantity refers to the ore quantity to be extracted according to the design in the balance sheet; its loss rate is one of the important indicators to reflect mining and technical management level.

Ore grade reduce due to mixture of waste ore and loss of rich ore powder during the mining process is called dilution. Dilution rate is generally adopted to represent the variation degree of ores from quality during the mining process. It is the reduced percentage of ore grade during the mining process.

Loss and dilution indicators are involved in a series of problems such as utilization of mineral resources, product quality and quantity, technology rationality, cost as well as management level. They must be attached great importance to as they directly influence the economic benefits of enterprises.

\subsubsection{Traditional Loss Rate and Dilution Rate Calculation}

Calculating unit of mining loss rate and dilution rate is usually the loss and dilution during the whole mining process from mining preparation and cutting of mining field, stoping, filling, ore drawing until transporting ore to pithead (or opencast mining field).

As for underground mine, the loss rate and dilution rate in the whole mining field shall be calculated according to the stoping procedures, chambers and pillars by using one mining field as a calculating unit, starting actual measurement with each stoping layer, as well as accumulating the calculated results of each layer [3]. As for the opencast mine, loss rate and dilution rate shall be calculated respectively according to the stope face, and then steps and ore blocks.

There are various calculation methods for loss rate and dilution rate according to different functions [4], and direct method and indirect method therein are usually adopted at present.

1) When direct method is adopted for calculation, during the process of stoping, catalog, sampling and actual measurement of layer (generally, $3 \sim 5 \mathrm{~m}$ is a stoping layer) shall be conducted timely, geological plan view of layer shall be compiled, orebody shall be delineated according to the laboratory data, extracted ore quantity, waste ore quantity and un-extracted ore quantity of layer shall be calculated according to the mining design, and then loss rate and dilution rate of layer shall be calculated [5] (namely, primary loss rate and dilution rate).

Calculation formula of loss rate: $\mathrm{P}=\mathrm{D} / \mathrm{Q} \times 100 \%$, where,

$\mathrm{P}$-Loss rate \%;

D-Lost ore quantity t;

Q-Geological ore reserves t.

Calculation formula of dilution rate: $\mathrm{r}=\mathrm{R} / \mathrm{T} \times 100 \%$, where,

$\mathrm{r}$-Dilution rate, \%;

$\mathrm{R}$-Total quantity of waste ore mixed into the mining field, t;

$\mathrm{T}$ - Total quantity of extracted ores and waste ore in the mining field, $\mathrm{t}$.

2) When indirect method is adopted for calculation, ore output grade and ore output quantity as well as corresponding geological ore quantity and geological grade shall be calculated through the continuous statistic data of ore output sampling (hopper and ore car in the mining field) and ore output metering (direct metering and ore car metering) in the mining field, and then loss rate and dilution rate shall be calculated according to the calculation formula (when wall rock is possessed of a certain grade, wall rock grade shall be calculated).

Calculation formula of indirect method:

$\mathrm{P}_{\text {Indirect }}=(1-\mathrm{T} / \mathrm{Q}) \times\left(\mathrm{C}-\mathrm{C}_{2}\right) /\left(\mathrm{C}_{1}-\mathrm{C}_{2}\right) \times 100 \%$, where,

$\mathrm{P}_{\text {Indirect }}-$ Metal loss rate in the mining field, \%;

$\mathrm{T}$ - Total quantity of ore output in the mining field, $t$;

Q-Geological ore quantity in the mining field, $t$;

C-Geological ore quantity grade in the mining field, $\mathrm{g} / \mathrm{t}$

$\mathrm{C}_{1}$ - Ore output grade in the mining field, g/t;

$\mathrm{C}_{2}$ - Grade of wall rock mixed into the mining field, $\mathrm{g} / \mathrm{t}$;

When wall rock is without grade, it can be simplified to the following formula:

$$
\begin{aligned}
& \mathrm{P}_{\text {Indirect }}=\left(1-\mathrm{T} \times \mathrm{C}_{1} / \mathrm{Q} \times \mathrm{C}\right) \times 100 \% \\
& \mathrm{r}_{\text {Indirect }}=\left(1-\mathrm{C}_{1} / \mathrm{C}\right) \times 100 \%,
\end{aligned}
$$

where, $r_{\text {Indirect }}-$ Dilution rate of mining field calculated 
by indirect method, \%;

C-Geological grade of extracted ore;

$\mathrm{C}_{1}$ - Ore output grade in the mining field.

Loss rate and dilution rate shall be calculated by midsection (stage) and pithead (mining field) according to the mining methods and stoping procedures, on the basis of nugget as the calculation unit.

\subsubsection{Acquisition of Calculation Parameters for Underground Mining Loss Rate and Dilution rate}

As for the calculation parameters acquired through direct method, specialized technical personnel (geological, measuring and mining) as well as production management personnel shall enter into the blasting layer of the mining field, collect and measure various data, calculate loss rate and dilution rate according to the layer of the mining field, instruct the mining operation, as well as find out the positions and reasons that cause loss and dilution. It is featured by higher accuracy (refers to primary dilution rate and mining loss rate) and timely calculation. It is mainly applied to the mining field stoped by such mining methods as short-hole shrinkage stoping, filling method, full mining method and room-and-pillar method [6].

All calculation parameters of loss rate and dilution rate shall be designed on the mining design drawing. Extraction and inbreak scope shall be designed according to the delineation scope of orebody, measured with ruler and planimeter, and then calculated according to the formula.

As for the calculation parameters acquired through indirect method, specialized technical personnel (geological, measuring and mining) as well as production management personnel can not or need not enter into the mining field to directly measure such parameters as extracted ore quantity, wall rock quantity and waste ore quantity. The method for calculating dilution rate and loss rate by comparing extracted rock quantity and grade measured with indirect method with the calculated industrial ore quantity and grade is called indirect method.

Indirect method can be used to calculate the dilution rate and loss rate of any mining method. The reliability of calculated results adopted through indirect method is poor due to large workload, long operation time as well as the influence of human factors and mineralization nonuniform.

\subsection{Working Theory and Method of the Calculation and Management for Mining Loss and Dilution under 3D Visualization Technical Condition}

The development of the image simulation technology and the 3D-GIS technology in late 1980s promoted the development of the three-dimensional visualization tech- nology of mining industry, a large number of CAD system softwares and geologic mining softwares were published successively and they were extensively used in the geologic and mining areas by the western developed countries. Currently, the commonly-used mining softwares are: Minesight of American Mintec Company, Micromine of Australia, Surpac of Surpac Software International (SSI), Datamine \& Guide of British MICL Company, as well as the domestic Dimine software independently developed by Digital Mine Corporation.

In order to give full play to the function of modern mining software, during the application study process of mine production technology informatization, the authors utilize the 3D model of geological resources and production mining system, as well as explore calculation and management for mine production loss and dilution under 3D visualization technical conditions according to the theory and method of loss and dilution, to improve calculation and management level for loss and dilution, simplify the calculation process, reduce work load, as well as release engineering technical personnel from complicated drawings and data collection and calculation.

\section{Example of Calculation}

As an example, authors choose Yangshu Gold Mine in Liaoning Province to research calculation and management for loss and dilution under 3D visualization conditions.

\subsection{Brief Introduction of Yangshu Gold Deposit}

Yangshu Gold Deposit lies in the east of Qingchengzi nappe slip surface, the plunging end of Bangzigou plunging anticline, to the south is Dadingzi granite, to the east is Jianshanzi fracture. Gaojiapuzi Yangshu Gold Deposit bullion polymetallic deposit occurred in the interbedding zone around the contact zone of Dashiqiao formation top and Gaixian formation. No. I gold orebody is mainly occurred at the top and bottom of $d_{3}^{5}$ dolomite marble, extended partially to the garnet mica granulite at the top of $d_{3}^{4}$.Laminarization and stratification of orebody are skew in small angles. Orebody is output in the shape of " " due to the control of stratum fold. Continuous total length of orebody is $600 \mathrm{~m}$; vertical thickness is $2 \sim 24 \mathrm{~m}$; depth expansion of controlled incline is $260 \mathrm{~m}$. Gold mine rocks are mainly silicified crushed alteration rocks. As the boundary between orebody and wall rock is obscure, it shall generally be delineated by samples. Mine production scale is $500 \mathrm{t} / \mathrm{d}$. When underground mining method is adopted, development method is vertical shaft development, and mining method is full mining method. 


\subsection{Establishment of Model}

\subsubsection{Establishment of Geologic Model}

In the establishment of geological models, although all the above softwares are different in the format of file data, the four most basic files applied in them are: Collar file, Survey file, Analysis file and Lithologies file. The process of establishment of geological models is follow: Firstly, the database is created by using the four files. According to idea of geology and mineralization, sectional interpretation is necessary to create the model. Three-dimensional geological models of orebody can be established with function of mining software. The secondary delineation of orebody is carried out by using the data of sinking and driving engineering during the production and mining process, thereby the grade III three-dimensional models of mine quantity and the nugget models in production and mining can be formed. Based on this, the authors designed the mining method and submitted the production department to organize the production and mining according to the characteristics ands of mining process. During the mining and production process, the data in geology, measurement as well as the mining and production engineering, geology and ore output shall be collected so as to accumulate data information for the three-dimensional management of loss and dilution.

\subsubsection{Formation of Three-Dimensional Models of Exhausted Area and Orebody Unit}

The tie lines of the frame of exhausted area are the interpretation line series of exhausted area formed from the acceptance survey data of mining field, the coordinates of the line knee points will be logged in a Excel table, the file of the interpretation line series in Miromine will be lead in. As shown in Figure 1.

The three-dimensional model of exhausted area is formed according to its interpretation lines (Figure 2, Figure 3). Whereafter, the line frame of this formed model of exhausted area will be checked. The line frame

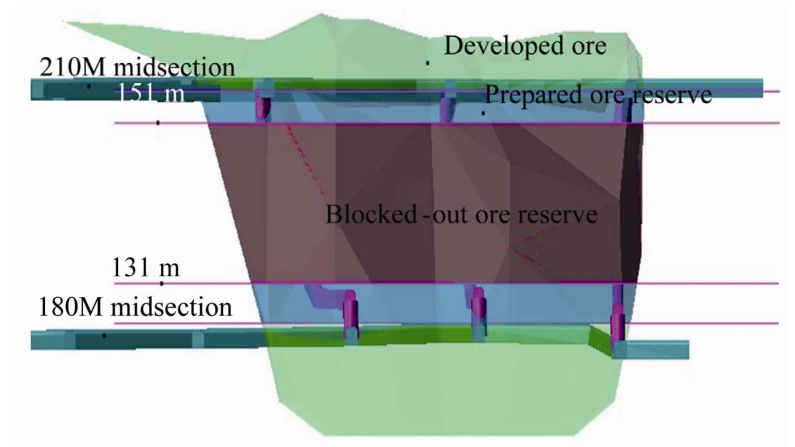

Figure 1. Distribution diagram of Grade-III ore quantity in orebody.

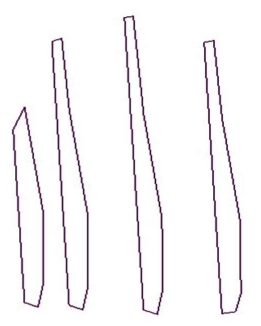

(a)

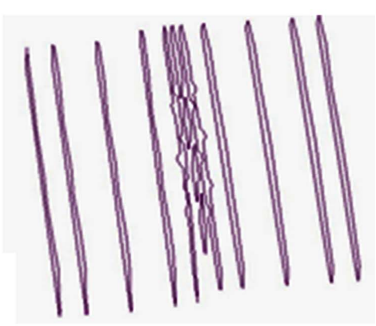

(b)
Figure 2. Line series of exhausted area. (a) Measured line series of exhausted area for the first time. (b) Ultimate formed line series of exhausted area.

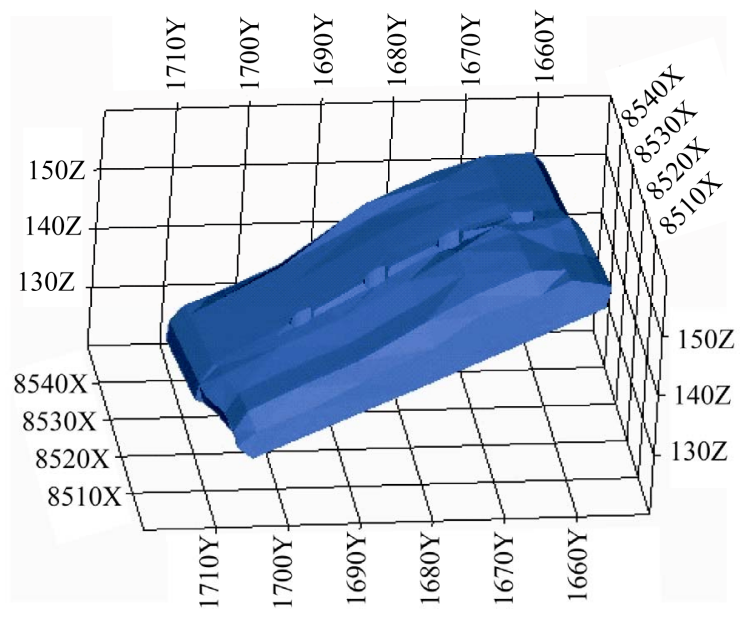

Figure 3. Three-dimensional model of exhausted area.

at the ore pillar part may be completed by breaking and connecting the tie lines to form a bifurcate line frame.

According to the physical geologic boundary of mining field, the secondary delineation will be conducted to the orebodies to form the tie lines of unit orebodies and establish the unit models of blocks in the mining field (Figure 4).

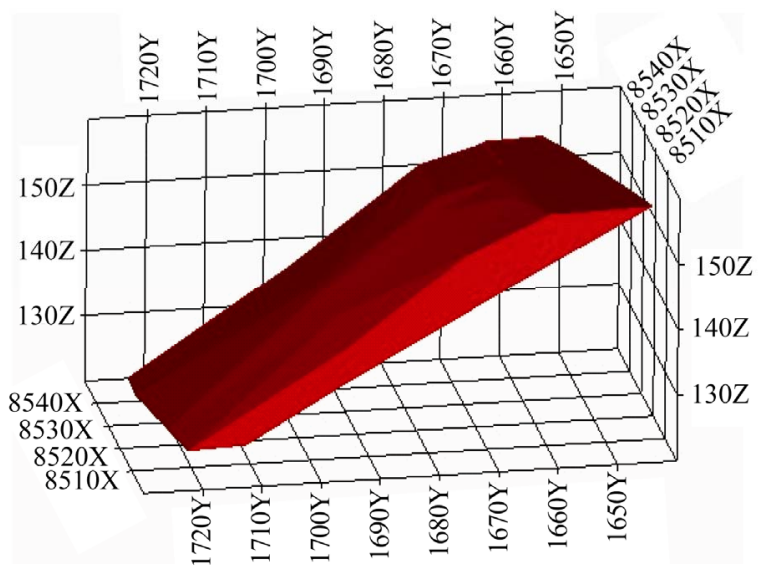

Figure 4. Unit model of orebody in mining field. 


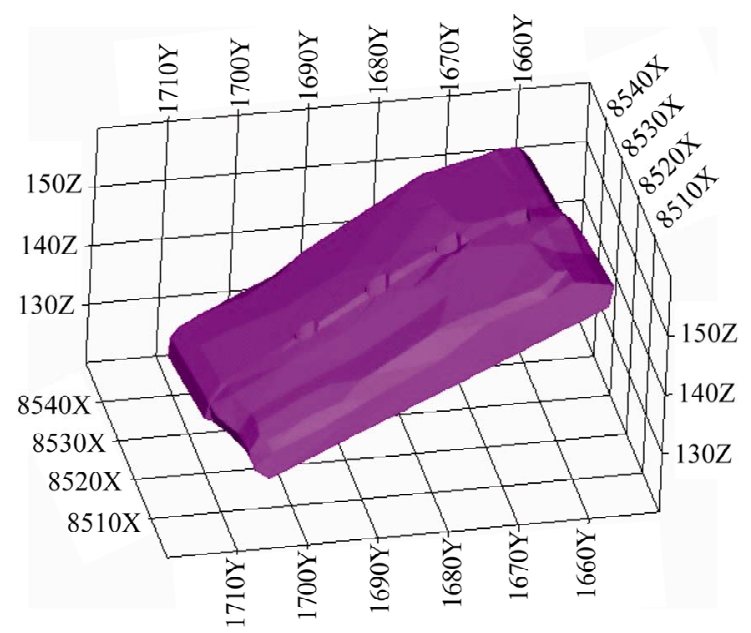

Figure 5. Model of extracted ore.

\subsubsection{Formation of Model of Exploitable Ore}

The solid model of exploitable ore shall be calculated through solid intersection operation with the models of exhausted area and blocks based on the solid intersecting function of Boolean calculation (Figure 5).

The solid line frame of waste ore shall be formed through the solid intersection operation with model of exhausted area and the wall rock at hangingwall and footwall based on the solid intersecting function of Boolean calculation (Figure 6 and Figure 7).

The model of waste ore quantity shall be formed through solid difference operation with the models of nugget and extracted ore based on the solid difference function of Boolean calculation.

\subsubsection{Calculation of Extracted Ore, Waste Ore and Ore Loss}

According to the models of orebody unit and the functions of the software, extracted ore, waste ore and ore loss, the ore quantity of nugget unit, waste ore quantity, ore loss and the gross amount of ore-bearing rocks shall be calculated in turn(Table 1), The calculation results are:

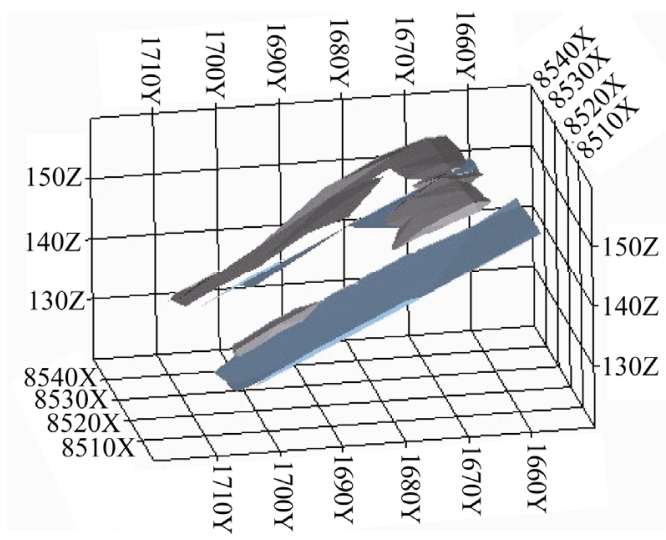

Figure 6. Model of Waste Ore.

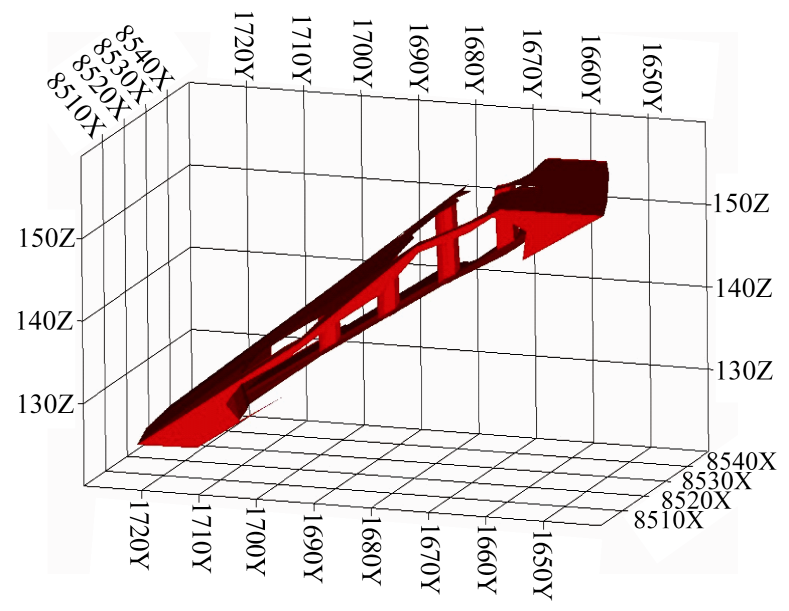

Figure 7. Model of ore loss.

Ore reserve of nugget: 39,291.68 t.

Extracted ore quantity: 29,353.01 t.

Gross amount of ore-bearing rocks is the sum of the extracted ore quantity and the waste ore quantity at the hangingwall and footwall.

The extracted waste ore quantity at hangingwall: $701.72 \mathrm{t}$.

The extracted waste ore quantity at footwall: $893.9 \mathrm{t}$.

Gross amount of extracted waste ore

$=$ quantity of hangingwall waste ore + quantity of footwall waste ore

$=701.72+893.9=1595.62(\mathrm{t})$

Gross amount of ore-bearing rocks

= quantity of extracted ore + gross amount of extracted waste ore

$=29353.01+1595.62=30948.63(\mathrm{t})$

Ore loss:

Ore loss = ore quantity of nugget - quantity of extracted ore $=39291.68-29353.01=9938.67(\mathrm{t})$

\subsubsection{Calculated Loss Rate and Dilution Rate}

The loss rate of ore is directly calculated by using the percentage between the ore loss and the ore quantity of the actually delineated nugget with direct method.

$$
\begin{aligned}
\text { Loss rate } P & =\frac{\text { Ore loss }}{\text { Ore quantity of nugget }} \times 100 \% \\
& =\frac{9938.67}{39291.68} \times 100 \%=25.3 \%
\end{aligned}
$$

Table 1. The calculation results of Loss/dilution Parameters.

\begin{tabular}{ccc}
\hline Type & WF-NAME & Tonnage (t) \\
\hline Loss/Dilution & 610 Nugget & $39,291.68$ \\
Loss/Dilution & 610 Extracted Ore & $29,353.01$ \\
Loss/Dilution & Extracted Hanging Wall Rock & 701.72 \\
Loss/Dilution & Extracted Foot Wall Rock & 893.90 \\
\hline
\end{tabular}


Similarly, the dilution rate also is directly calculated by using the percentage between the quantity of extracted waste ore and the gross amount of ore-bearing rocks with the direct method.

$$
\begin{aligned}
& \text { Dulution rate } Q \\
& =\frac{\text { Quantity of extracted waste ore }}{\text { Gross amount of ore-bearing rocks }} \times 100 \% \\
& =\frac{1595.62}{30948.63} \times 100 \%=5.16 \%
\end{aligned}
$$

\section{Discussion and Conclusions}

It is practical to establish the geological models of various phases by using the actual geologic and mining data of mines and to calculate the loss rate and dilution rate of the mining fields with these models and modern mining softwares. Compared with the traditional method, the characteristics are 1) parameter calculation will not be different due to human factors (namely, arrangement and drawing), so parameter calculation will be more accurate; 2) no matter what mining method is, direct method can be used for calculating loss and dilution with modern measuring technology; 3) work load of technical personnel is reduced greatly and work efficiency is improved obviously. It is worth the promotion and application of the mining enterprises. It must be worth notice that the real production data of the mines must be collected and arranged timely and comprehensively to establish a intact precise database when establishing the three-dimensional models of the orebody units in exhausted area and mining field so as to accurately obtain the physical boundary of exhausted area as well as the loss and dilution quantity during the mining process, and the precise calculation of the loss and dilution indicators of mining fields is realized through the Boolean calculation among models.

\section{REFERENCES}

[1] M. Yunliang, G. Fuying and M. Zhanwu, "Strengthening the Technical Cooperation to Reduce Loss and Dilution Rates,” Express Information of Mining Industry, Vol. 17, 2000, pp. 34-39.

[2] Y. W. Chen, "The Calculation and Experience of the Mining Total Loss and Impoverishing Index," Gold Science and Technology, Vol. 6, 2002, pp. 21-30.

[3] X. X. Wang and H. Yu, "Optimise Ore Dilute and Loss Rate, Enhance Mine Economic Effectiveness,” Mineral Resources and Geology, Vol. 3, 2000, pp. 51-58

[4] D. C. Wang, H. C. Li and L. C. Zhao, "Discussion on Decrease of Loss and Impoverishment and Increase of Mining Recovery Rate," Conservation and Utilization of Mineral Resources, Vol. 4, 2003, pp. 96-103

[5] B. R. Zhang, S. F. Huang, et al., “Gold Mining Geology,” Geology Publishing House, London, 2010, pp. 254-259.

[6] J. B. Chen, "Measures for Reducing Loss and Dilution in Underground Mining," Industrial Minerals and Processing, Vol. 3, 2004, pp. 89-95. 